\title{
Marital Satisfaction, Age And Alcohol Use During Pregnancy: An Empirical Study Of Pregnant Women In Uyo Metropolis, Nigeria
}

\author{
James E. Effiong \\ Department of Psychology, University of Uyo, Nigeria \\ Okokon O. Umoh \\ Department of Psychology, University of Uyo, Nigeria \\ Center for Research and Information \\ on Substance Abuse (CRISA), Uyo, Nigeria
}

Adedeji J. Ogunleye

Department of Psychology, Ekiti State University, Ado Ekiti, Nigeria

doi: 10.19044/esj.2016.v12n11p241 URL:http://dx.doi.org/10.19044/esj.2016.v12n11p241

\begin{abstract}
A convenient sampling technique was used to draw a sample of 110 pregnant women reporting for antenatal clinical checks in both private and public medical facilities in Uyo, Nigeria to investigate marital satisfaction and age as predictors of alcohol use during pregnancy. Kansas Marital Satisfaction Scale was used in dichotomizing respondents into satisfied and dissatisfied pregnant women in marriage, while an item in Alcohol Use Disorder Identification Test (AUDIT) delineated our cohorts into users and non-users of alcohol. A 2x2 factorial design was adopted as regards the plan of the study while a 2-way analysis of variance was used for the analysis of data collected. Results confirmed the first hypothesis which predicted that pregnant women who are satisfied in their marriages would report less alcohol use than their dissatisfied counterparts $\{F(1,104)=4.70 ; \mathrm{p}<.05\}$. Findings also confirmed our second hypothesis which stated that pregnant women who are younger would report more alcohol use than their elderly counterparts $\{F(5,104)=11.833 ; p,<.05\}$. Discussion of findings centered on the theories of learning which formed the nucleus of this paper and it was recommended that intervention would benefit from effective and affordable psychological counseling and treatment services for women exposed to harmful and/or hazardous alcohol use predicated by marital distress, violence, depression as well as those with limited coping skills.
\end{abstract}

Keywords: Pregnancy, marital satisfaction, alcohol use, age, Nigeria 


\section{Introduction}

Alcohol consumption is one of the modifiable risk factors for poor pregnancy outcomes in Nigeria (Ordinioha\&Brisibe, 2015). The chronic physical, biological and cognitive hazards posed by alcohol consumption to pregnant women and their unborn babies have received public health attention in recent times (Krulewitch, 2005). Despite global efforts at minimizing its use, the prevalence of alcohol consumption among this cohort (pregnant women), across cultures is higher than commonly realized (Mellingen, Torsheim\&Thuen, 2013). Empirical data from the United States and Canada reveal that between $11 \%$ and $12 \%$ of women consume alcohol during pregnancy (Stagerstrom, Chang \& Nelsen, 2011). A higher prevalence rate of $23 \%$ to $54 \%$ has been reported in Europe (Bakhireva, Wilsnack, Kristjanson, Yuvtushok, Onishenka, Werteleck, \& Chambers, 2011). Between 1991 and 2005, an earlier finding has it that about 1 in 8 (12.5\%) of these cohorts were found to be involved in alcohol use (Center for Disease Control and Prevention, 2009). Recent data from Substance Abuse and Mental Health ServicesAdministration (SAMHSA, 2013) reveal an upward trend as the percentage of pregnant women's admissions reporting alcohol abuse between 2000 and 2010 (with or without other drug abuse) has been confirmed to dangle between $34.8 \%$ and $46.6 \%$. In Nigeria, heavy drinking was found in 38\% of women currently drinking (Martinez, Roislein, Naidoo \& Clausen, 2011).

Although the etiology of drug and alcohol abuse during pregnancy remains unclear, studies ( e. g., Ducci\& Goldman 2008; Morozova, Goldman, Mackay \&Anholt, 2012)have revealed a significant genetic basis for alcoholism, particularly among pregnant women, with a penetrance of $50 \%$ to $60 \%$ (Wilson \& Thorp, 2008). Whether or not the genetic model is supported, alcohol use, abuse and/or dependence, in our sample,is best approached from the bio-psycho-social paradigm. This paradigm supposes that alcoholism is a problem resulting from a complex interaction of an individual's biological, psychological, cognitive (beliefs, thought, learning), and environmental (social, cultural and economic etc.) factors.

While not ignoring the potency of psychopathology and cognitive approaches, our attempt at explaining the relationship between marital dissatisfaction and drinking among pregnant women places this paper in the perspectives of three learning paradigms which would direct the course of our discussion: the operant conditioning model (Skinner, 1948) and the classical conditioning (Pavlov, 1960), social learning theory (Bandura, 1961), and the psychodynamic model (Freud, 1934)

According to the psychodynamic model, women with mental health disorders, reproductive problems, and eating disorders appear more likely to develop substance abuse problems. Depending on the time, day, trimester, 
event etc., most pregnant women experience intense emotional states on a continuum ranging from feeling of excitement and happiness at one end, and feelings of concerns and anxiety on the other (Periera, Lousia, Lima, Legay, Santos, Santos, Thiago \& Valencia, 2011).

The relevance of partner relationship, in terms of marital satisfaction has been implicated in spouses' psychological health; notably, depression, anxiety and alcohol abuse, (Whismas\&Webelacker, 2006); physical health, (Rekolt, Glazer \& Newton 2001), and children's well being (Amato \& Keith 1991). In essence, Bachman, Wadsworth, O’Malley, Johnstone and Schalenberg, (1997), and Temple, Fillmore, Hartka, Johnstone, Leino and Moloyoski (1991) independently confirmed, in their community surveys of smokers, drinkers and drug users, that marital dissatisfaction and change in marital and employment status do predict increased drinking among women. Corroborating the above reported findings, Whisman, Uebelacker and Bruce, (2006), examined about 1700 married men and women without alcohol disorder over twelve months and the baseline marital dissatisfaction predicted the occurrence of an alcohol disorder after controlling for lifetime alcohol disorders. Marshal (2003) found that studies with sufficient variability in measures of alcohol consumption and sample sizes reported significant negative correlations between alcohol consumption and marital satisfaction. He also found considerable evidence that alcoholics in treatment and their spouses have lower levels of marital satisfaction than appropriate groups, and that the marital interaction of alcoholics and their spouses were also indicative of poor marital functioning. Testa and Leonard's (2001) study also add necessary impetus to our preceding empirical literature in their study of the impact of marital aggression on women psychological and marital functioning. After controlling for demographic variables, they found that women who experienced intimate partner violence during their first year of marriage reported a greater frequency of heavy drinking episode. In consonance with the community sample studies reported above, there is clear evidence that marital distress has an adverse impact on drinking among female alcoholics in treatment. Couples who failed to complete conjoint alcoholism treatment did have lower levels of commitment to marriage (Epstein, McCrady, Miller and Steinberg, 1994).

In terms of age, available literature suggests that drinking among women is most common between the ages of 26 and 34 years, while binge drinking is most common in women aged 18 - 25 years (CDC, 2009).

Another study by Meschke, Holl, and Messelt (2012) showed patterns of relationship between maternal age and prenatal alcohol consumption. In their study to investigate the potential risk factors associated with prenatal alcohol use by maternal age, using a survey data derived from a sample of 9,004 pregnant women from the North central U.S, Meschke et al 
reported that teens in general had a higher level of occurrence of risk factors identified with prenatal drinking compared with older women of advance maternal age (35 years or older) and as such were more likely to drink alcohol during pregnancy. This finding suggests that younger women are more likely to drink, binge drink and face a greater risk of meeting the DSM - IV criteria for alcohol abuse than older women. Younger women's pregnancies, particularly teens, are more likely to be unintentional and recognized later, thus increasing the risk of prenatal drinking to wade off possible depressions associated with unplanned/unwanted pregnancy. This submission is based onanecdotal evidences which suggest substance use as assumed remedy for depression. Mellingen, Torsheim and Thuen (2013) in their exploration of changing alcohol use and relationship satisfaction in Norwegian couples found that among elderly women, the likelihood of belonging to the high and chronic alcohol use group increased with age. Similarly, an earlier study in France found evidence that women in the older generation drank more than the younger women (Zins, Gueguen, Leclers\&Golberg, 1991). This high drinking pattern may be explained by the high level of marital stress or strain in household management and possible changes in the pattern of kin network as a woman grows older as well as the length of time of association with drinking partner.Other studies have also shown joint effects of marital stress and age on maternal alcohol consumption.

Our review of literature reveals that little has been done in the area of maternal drug use and marital satisfaction; especially in the Nigerian setting. This explains why most works cited in this study do have western background. If this study effectively probes into possible connectivity between our variables of interest in the Nigerian culture, thus informing future research aimed at decreasing this maladaptive practice and its attendants among our population of interest, the aim of this work would have been achieved. Based on the foregoing, it became necessary to hypothesize that:

1. Pregnant women who are satisfied in their marriages would report less alcohol consumption than their non-satisfied counterparts.

2. Younger pregnant women would report more alcohol use than their elderly counterparts.

\section{Method}

\section{Participants}

Convenient sampling technique was used to draw a sample of 110 pregnant women reporting for prenatal clinical checks in both private and public medical facilities in Uyo, Nigeria. Questions about participant's behaviour or experiences, such as alcohol consumption and marital 
satisfaction, relied on individual responses. Sample had an age range of 15 40 years and a mean of 28.47 years. About 33 (30\%) of the sample abstained from alcohol before pregnancy while 77 (70\%) reported using alcohol prior to pregnancy. Alcohol using women during pregnancy were 50 (45\%) compared to 60 (55\%) who abstained from alcohol use during pregnancy. Information elicited from participants' educational backgrounds revealed that 52 (47\%), though had some level of education, but, had no formal University education while 58 (53\%) had equivalent of first degree and above. About 5(4.5\%) respondents were between the ages of $15-20$ years. A vast majority of respondents (32; 29\%) fell between the ages of 21 and 25 years. Respondents between the ages of 26 and 30 years were 33(30\%). 28(25\%) were between 31 and 35 years, 12(10\%) of the respondents fell within the 36 to 40 age range.

\section{Measures}

Kansas Marital Satisfaction Scale (KMSS) developed bySchumm, Nicholes, Schectman\&Grigsby(1983) probed into participants' marital satisfaction status. It is a 3-item, 7-point Likert scale that sought to know participants' satisfaction with the spouse, marriage and relationship. Items on the measure are: (1) How satisfied are you with your husband? (2) How satisfied are you with your marriage? And (3) How satisfied are you with your relationship with your husband? Response format for each item ranges from 1 to 7 . Respondents were instructed to supply one of seven numbered response categories ranging from extremely dissatisfied to extremely satisfied. Scoring is the total sum for the individual items. Higher score above a mean score of 12 indicates high level of marital satisfaction while lower score indicate low level of marital satisfaction (Schumm, Scanlon, Crow, Green \& Buckler, 1983). Total score ranges from 3 to 21. Cronbach's Alpha for this scale is .84 with test-retest reliability as .71 (Schumm, Bollman, \&Jurich, 1985).

Age of respondents was classified into the following age categories: 15-20, 21-25, 26-30, 31-35, 36-40, 40 and above for respondents to choose from. Participants within the age brackets of 15 and 30 years fell into the younger pregnant women category while those above the aforementioned age brackets were classified into the older pregnant women group.

Alcohol use responses were elicited from respondents by asking a question adopted from Alcohol Use Disorder Identification Test (AUDIT). Alcohol Use Disorder Identification Test developed by Babor, HigginBiddle, Saunders\& Monteiro in 2001 is a 10-item questionnaire. Since the researchers' interest was to establish the drinking status of respondents by categorizing them into users and non-users, the researchers had to adopt item 1 in the scale which asks: "How often do you have a drink containing alcohol 
in the past twelve months?" with the response categories of 'never', 'monthly or less', '2 to 4 times monthly', '2 to 3 times a week' ' 4 or more times a week.Thus responses of 'never' were elicited from non-drinkers, while other responses depicted drinkers and were accordingly classified into appropriate category.

\section{Research Design/ Data Analysis}

The study adopted a 2 × 2 factorial design. The use of this design was necessitated by the fact that the independent variables of interest (marital satisfaction and age) were perceived from two level (satisfied/not satisfied and younger pregnant women/older pregnant women) respectively. Thus a 2 $\mathrm{x} 2$ factorial design is considered appropriate in the comparison of the mean differences of these independent groups. A2-way analysis of variance was employed in data analysis. Descriptive statistics (means, standard deviations, and percentages) were also used in describing our sample vis-a-viz other variables of interest.

\section{Procedure}

Approval to conduct this study in various health institutions was obtained from the heads of such institutions, who assigned knowledgeable persons to assist researchers in conducting the survey. Informed consent was sought from respondents selected to participate in the study. Respondents were briefed of the aim of the study before questionnaires were administered and confidentiality was assured. Information was gathered anonymously such that responses could not be traced to any particular respondent. Respondents were encouraged to work independently to avoid undue influence of their opinions by friends during decision making. A hundred and fifty (150) questionnaires were administered. Of these, 30 were discarded on the basis of not being properly filled and about 10 could not be retrieved. Altogether,110 questionnaires were left for data analysis.

\section{Results}

This section presents descriptive and inferential data of the variables of interest of this study.

Table1: Table of means and standard deviations of marital satisfaction and age on alcohol use among pregnant women.

\begin{tabular}{cccc}
\hline & \multicolumn{2}{c}{ Marital Satisfaction } & \\
\hline \multirow{2}{*}{$15-30$ years } & Dissatisfied & Satisfied & Sum $(\mathrm{X})$ \\
& $\mathrm{X}=5.3$ & $\mathrm{X}=3.4$ & 8.7 \\
Age & $\mathrm{SD}=1.0$ & $\mathrm{SD}=1.6$ & \\
Above 30 year & $\mathrm{n}=55$ & $\mathrm{n}=12$ & 6.6 \\
& $\mathrm{X}=4.6$ & $\mathrm{X}=2.0$ & \\
Sum $(\mathrm{X})$ & $\mathrm{SD}=1.0$ & $\mathrm{SD}=0.7$ & 15.3 \\
\hline
\end{tabular}


Table showing mean differences between our variables of interest (table 1) reveals a slight difference in mean alcohol consumption between the maritally dissatisfied and the satisfied pregnant women (9.9 vs 5.4). The consumption of alcohol between younger pregnant women (between 15 - 30) and those above 30 years is also different (8.7 vs 6.6). Younger women in their early years (15-30) tend to drink more than their elderly counterparts during pregnancy.

Table 2: Summary Table of 2-way Analysis of Variance for marital satisfaction and age on prenatal alcohol consumption

\begin{tabular}{cccccc}
\hline Source & SS & df & MS & F & P \\
\hline Corrected Model & 6.230 & 10 & .623 & 24.401 & .012 \\
Intercept & 63.799 & 1 & 63.799 & 249.89 & .00 \\
Marital & 1.201 & 1 & 1.201 & 4.70 & $<.05$ \\
Satisfaction & & & & & \\
Age & 3.021 & 5 & .604 & 11.83 & $<.05$ \\
Marital & .04 & 4 & .010 & .162 & $>.05$ \\
Satisfaction & & & & & \\
Age & 271.000 & 105 & & & \\
Total & & & & & \\
Corrected Total & 30.229 & 104 & & & \\
\hline
\end{tabular}

Table 2 reveals a significant difference in alcohol consumption between pregnant women who are satisfied in their marriages and their nonsatisfied counterparts $\{\mathrm{F}(1,104)=4.70 ; \mathrm{p}<.05\}$. The direction of our stated difference is captured by our mean table (table 1) which indicates that maritally dissatisfied women drink more than their satisfied counterparts during pregnancy ((9.9 vs 5.4).

We also noticed the confirmation of our second hypothesis which predicted that pregnant women who are younger would report more alcohol use than their elderly counterparts $\{F(5,104)=11.833 ; p<.05\}$. There was however no relation between maternal marital satisfaction, age and alcohol use among pregnant women $\{\mathrm{F}(4,104)=.162 ; \mathrm{p}<.05\}$.

\section{Discussion}

This study explored possible psychological and demographic contributors (marital satisfaction and maternal age) to maternal drinking during pregnancy. It aimed at finding out if these variables are capable of impinging on the alcohol use status of pregnant women in our vicinity. Findings support our first hypothesis that pregnant women who are satisfied in their marriages would report less alcohol consumption than their nonsatisfied counterparts.

Younger mothers (those between the ages of 15 and 30 years) also reported more drinking than women in the older age brackets (above 30). 
Many previous research works tend to lend credence to our findings on the role of marital satisfaction in alcohol drinking among pregnant women: (Bachman, Wadsworth, O’Malley, Johnstone \&Schalenberg, 1997; Temple, Fillmore, Hartka, Johnstone, Leino\&Moloyoski, 1991). Our findings are also supported by Whisman, Uebelacker and Bruce, (2006) who, after following pregnant women without alcohol disorder over twelve months reported that the baseline marital dissatisfaction predicted the occurrence of an alcohol disorder. Testa and Leonard (2001) also found that women who experienced intimate partner violence during their first year of marriage reported a greater frequency of heavy drinking episode. Esptein, McCrady, Miller and Steinberg's (1994) reported as well and to buttress our present findings that, couples who failed to complete conjoint alcoholism treatment did have lower levels of commitment to marriage.

Our second hypothesis that predicted possible connectivity between maternal age and alcohol consumption is supported by some extant studies. Center for Disease Control and prevention (2009) posited that drinking among women is most common between the ages of 26 and 34 years, while binge drinking is most common in women aged 18 to 25 years. Also, Meschke, Holl and Messelt (2012) reported that teens in general had a higher level and greater occurrence of risk factors identified with prenatal drinking compared with older women of advance maternal age.

In our quest to probe into possible causes of drinking among pregnant women, we had chosen to place this study within the purviews of behavioral paradigms (Operant conditioning - Skinner, 1948; Classical conditioning Pavlov, 1960; and the Social Learning Theory - Bandura, 1977). Operant conditioning is a method of learning that occurs through reinforcements and punishments for behaviors. Through this paradigm, an association is established between behaviour and consequence for that behavior. Thus, pregnant women's behaviors are always shaped by the consequences of drinking. If behavior is positively reinforced, it is likely to be repeated.

Positive reinforcement triggers the dopamine release in the mesolimbic dopamine systems. The system is designed for natural reinforcers such as alcohol, which causes massive over- stimulation of dopamine receptors and therefore positively rewarded. Thus humans continue to behave in certain ways if they get positive consequences for the behavior. Additionally, if a pregnant woman's social group drinks heavily and she gets positive feedback from friends for drinking the same way, she will be more likely to continue the pattern. If a person gets other rewards from drinking - for example, she is more social or less anxious - she may also learn to use alcohol as a way of getting that reward or as a way of coping with uncomfortable, stressful and/or painful experiences that may culminate into marital dissatisfaction. 
Pavlov's (1960) classical conditioning is a form of associative and involuntary learning which proposes that if a conditioned stimulus (CS) is constantly paired with an unconditioned stimulus (US), after some time, the originally conditioned stimulus (CS) will begin to produce an unconditioned response (UR) similar to that which was elicited by the unconditioned stimulus before the pairing of both stimuli. Thus, Pavlov's idea suggests that maternal drinking (CR) in pregnancy does not occur in isolation, but triggered by certain personal, psychological and/or situational cues. These cues (e. g, loneliness, family stress, etc.) are the conditioned stimuli which create powerful craving which lead to drinking.

Social Learning Theory (Bandura, 1977) posits that we can learn and make associations in a social context, simply by observing and imitating the behaviors of others. The behavior(s) being observed are most likely to be repeated if reward is part of the observation. For example, pregnant women who watch their peers drink, laugh, and have fun will pair that association and increase the likelihood that she will attempt the behavior as well.

\section{Practical Implications of Results and Suggestion for Policy Implementation}

Aside from its social implications, the teratogenic effects of maternal alcohol consumption during pregnancy could be viewed in the light of dysphonation (Nugent, Lester, Greene \&Weeczoreck-Deering, 1996) and anomalies of craniofacial structures derived from the cranial neural crest cells (Bell, Rayes-Greenow, Bower, Turner, Robert, \&Nassar, 2013). Prenatal exposure to alcohol through the pregnant mother's drinking is a leading preventable cause of fetal malformation, such as Partial Fetal Alcohol Syndrome (PFAS), Fetal Alcohol Spectrum Disorders (FASD), and the more severe Fetal Alcohol Syndrome (Aliyu, Lynch, Nana, Alio, Wilson, Manty, Zoorob\&Salittu, 2011; De Wulp, Hoving\& De Veries, 2014; WHO, 2011). Maternal alcohol consumption during pregnancy has also been implicated in childhood conduct problems (Science Daily, 2007), as it is also known to be a leading cause of childhood acute myeloid leukemia (LatinoMartel, Chan, Druesue-Pecollo, Barrandon, Hercberg\&Norate, 2010). Increased risks of alcohol related outcomes during pregnancy also include spontaneous abortion, stillbirth, preterm delivery, neonatal death, sudden infant death syndrome, prenatal and postnatal growth deficiencies, as well as cognitive and behavioral deficits (Kesnodel, Wisborg, Olsen, Wenriksen\&Secher, 2002; Aliyu, Zynch, Nana, Alio, Wilson, Marty, Zoordb\&Salith, 2001; O’Leary, C, Nassar, Kurinczuk, and Brower, 2009 ). Extant literature corroborates our findings in the revelation that a wide variety of pregnant women use alcohol and this points to the necessity of turning further research interest to factors that do not only exacerbate 
addiction, but those that impede the progress of addiction intervention programs in the country. Apart from contributing to the scarce resources on marital satisfaction, maternal age and alcohol consumption among pregnant women, this paper also re-echoes the drinking trend among this cohort. Learning models have been used to identify possible triggers of drinking among pregnant women; paradigms wherein also lie the solutions. A cursory look at the psychological component of our preferred paradigm indicts life stressors in the course of pregnancy, poor coping skills (where majority may turn to alcohol to cope with violence, depression, poverty, isolation etc.), limited social support systems (Stagerstrom, Chan, \& Nelsen, 2011; Liew, 2012), easy access to alcohol and illicit substances, previous traumatic crises, and identity/self-esteem problems in susceptibility to prenatal alcohol consumption.

It is expected that findings of this study will redirect stakeholders' attention to incorporate techniques provided by these theories - cue exposure (cues associated with addiction eg., sights, smells, location, people) aversive therapy, assertiveness training, etc- in the drug ongoing intervention plans proposed by the European Union to tackle drug problems in Nigeria. This could be juxtaposed with full psychological service centers that would provide effective but affordable counseling services for those exposed to marital distress, violence, depression, limited coping skills, etc as well as those not exposed to such. Focus of such strategy should also be on younger women as they are more vulnerable to addiction.

\section{References:}

Aliyu, M. H., Lynch, O., Napa P. N., Alio A. P., Wilson R. E., Marty P. J., Zoorob R., Salihu H, M. (2011). Alcohol consumption during pregnancy and risk of placental abruption and placenta preuia.Maternal Child Health, 15(5): 560-576.

Alvik A., Heyardahl S., Haldorsen C, \&Linderman R. (2006). Alcohol use before and during pregnancy: a population-based study. ActaObstericaetGynecologicaScandinauica, 851292 - 1298.

Bachman, J. G., Wadworth, K. N., O’Malley, P. M., Johnston, L. D. and Schulenberg, J. D. (1997).Smoking, Drinking, and Drug Use in Young Adulthood: The Impact of New Freedom and New Responsibilities. Mahwah, New Jersey: Erlbaum.

Bakhireva, L., Wilsnack, S.,Kristjanson, A.,Yuvtushok, L., Onishenko, S., Werteleck, W. and Chambers, C. (2011). Journal of Studies on Alcohol and Drugs, 72 (8): 536 - 544.

Bandura, A. (1977).Social Learning Theory. Englewood Cliffs, NJ: Prentice Hall. 
Bell, J. C., Rayes-Greenow, C., Bower, C., Turner, R. M., Robert, C. L. and Nassar, N. (2013).Descriptive Epidemiology of Cleft Lip and Cleft Palate in Western Australia; Birth Defects Research Part A. Clinical and Molecular Teratology, 97,101 - 108 .

Centre for Disease Control and Prevention (2009). Alcohol use among pregnant and non-pregnant women of child-bearing age in United States: 1991 - 2005. Morbidity and Mortality Weekly Report MMWR 58:529-532.

De-Wulp, N., Hoving, C. and De Vries, H. (2014). Partner's Influences and other Correlates of Prenatal Alcohol Use.Maternal and Child Health Journal, 19(4): 1007 - 1014.

Ducci, F. and Goldman, D. 92008).Genetic Approaches to Addiction, Genes and Alcohol. Addiction, 103, $1414-1428$.

Epstein, E. E., McCrady, B. S, Miller, K. J., Steinberg, M. (1994). Attrition from Conjoint Alcoholism Treatment: Do Dropouts Differ from Completers? Journal of Substance Abuse, 6, 249 - 265.

Kesnodel U., Eisborg K., Olsen S. F., Heniksen T. B. \&Secher N. J. (2002). Moderate alcohol intake during pregnancy and the risk of stillbirth and death in the first year of life: American Journal of Epidemiology, 155, 305-313.

Krulewitch, C. J. (2005). Alcohol Consumption during Pregnancy.Annual Review of Nursing Research, 23, 101 - 134.

Latino-Martel, P., Chan, D. S., Druesue-Pecollo, N., Barrandon, E., Hercberg, S., and Norate, T. (2010). Maternal Alcohol Consumption during Pregnancy and the Risk of Child Leukemia: Systematic Review and Metaanalysis. Cancer Epidemiological Biomarkers and Prevention, 19 (15): 1238 $-1260$.

Liew, H. (2012). Effects of Marital Status Transition on Alcohol Use Trajectories.Logitudinal and Life Course Studies, 3 (3): 332 - 345.

Marshall M. P. (2003) For better or for worse? The effects of alcohol use on marital functioning.Clinical Psychol Revision.23: 959-97.

Martinez, P., Roislein, J., Naidoo, N \& Clausen, T. (2011).Alcohol Abstinence and Drinking among African Women; Data from the World Health

Survey.http://www.biomedcentral.com/1471 2458/11/160. Assessed; March, 142014.

Mellingen, S., Torsheim, T. and Thuen, F. (2013).Changes in Alcohol Use and Relationship Satisfaction during Pregnancy in Norwegian Couples.Substance Abuse Treatment, Prevention and Policy.http//Psychology.uiowa.edu/files. Assessed: January 28, 2015.

Meschke, l. L., Holl, J., Messelt S. (2012). Older not wiser: risk of prenatal alcohol use by maternal age. Maternal and Child Health Journal: DOI: 10:1007/s 10995-012-0953-7. 
Morozova, I. V., Goldman, D., Mackay, T. F and Anholt, R. H (2012). The Genetic basis of Alcoholism: Multiple Phenotype, many genes, complex Network. Genome Biology, 13, 239.

Nugent, J. K., Lester, B. M., Greene, S andWeeczoreck-Deering, D. (1996).Effects of Maternal Alcohol Consumption and Cigarette Smoking during Pre acoustic Cry Analysis.Child Development, 67 (4): 1805 - 1815.

O’Leary, C., Nassar, N., Kurinczuk, J., and Brower, C. (2009).Impact of Maternal Alcohol Consumption on Fetal Growth and Preterm Birth.British Journal of Obstetrics and Gynecology, 116; 390 - 400.

Ordinioha, B and Brisibe, S. (2015). Alcohol Consumption among Pregnant Women Attending the Ante - natal Clinic of a Tertiary Hospital in South South Nigeria. Journal of Clinical Practice, 18(1): 13 - 17.

Pavlov, I. P (1960). Conditioned Reflexes. New York, Dover.

Periera P. K., Lovisi G. M., Lima L. M., Legay L, F., Santos J. F., Santos S, A., Thiengo D. L. and Valencia E. (2011). Depression during pregnancy: review of epidemiological and clinical aspects in developed and developing countries. In T. Wehara (Ed);Psychiatric disorders - trends and development.Rijek: Intech Publishers.

Schuum, W. R., Bollman, S. R. and Jurich, A. P (1985).Criterion-related validity of Kansas Marital Satisfaction Scale. Psychological Report, 56, 719 $-222$.

Schuum, W. R., Scanlon, E. D, Crow, C. L., Green, D. N., 7 Buckler, D. L. (1983). Characteristics of the Kansas Marital Satisfaction Scale in a Sample of 79 Married Couples. Psychological Reports, 53, 583 - 588.

Schuum, W. A., Nichols, C. W., Schectman, K. L., and Grigsby, C. E (1983). Characteristics of Response to the Kansas Marital Satisfaction Scale by a sample of 84 Married Mothers. Psychological Report, 55, 569 - 572.

Science Daily (2007). Maternal Alcohol During Pregnancy is Associated with

Risk for

Childhood Conduct Problems. http://www.Sciencedaily.com/release/2007/11 /071105164441.htm. Accessed: 28 November, 2015.

Skinner, B. F. (1948). Superstition in the pigeon. Journal of Experimental Psychology, 38, 168-172.

Stagerstrom, J., Chan, G., \& Nelsen, P. (2011). Predictors of Drinking during Pregnancy: A Systematic Review. Journal of Women's Health, 20(6): 901 903.

Substance Abuse and Mental Health Services Administration (2013). Trends in substance Abuse Among Pregnant Women and Women of Child Bearing Age in Treatment. SAMHSA.http://www.samhsa.gov/data/DASIS.aspx\#TEDS. Acessed: 28 November, 2015 
Temple, M. T., Fillmore, K. M., Hartka, E., Johnstone, B., Leino, E. V.,Moloyoski, M. A. (1991). Meta-analysis of Change in Marital and Employment Status as Predictors of Alcohol Consumption on a Typical Occasion.British Journal of Addiction, 86, 1269 - 1281.

Testa, M. and Leonard, KE.(2001). Impact of Marital Aggression on Women Psychological and Marital Functioning in a newly Wed Sample.Journal of Family Violence, 16, 115 - 130.

Whisman, M. A.,Uebelacker, L. A., Bruce, M. L. (2006). Longitudinal Association between Marital Dissatisfaction and Alcohol Use Disorder in a Community Sample.Journal of Family Psychology, 20, 164 - 167.

Wilson, J. \& Thorp, J. (2008).Substance Abuse in Pregnancy.Global Library of Women's Medicine.

http://www.glowm.com/section_view/heading/substance.htm. Assessed, February, 2014.

World Health Organization (2011).Global Status Report on Alcohol and Health. Geneva: World Health Organization.

Zins, M., Gueguen, A., Leclerc, A., and Golberg, M. (1991).Alcohol Consumption and Marital Status of French Women in the GAZEL Cohort: A Longitudinal Analysis between 1992 and 1996. Journal of Studies on Alcohol and Drugs, 64 (6), 784 - 789. 